Sharif University of Technology
Scientia Iranica
SCIENTIA
I RAN I CA
Transactions A: Civil Engineering
www.scientiairanica.com

Invited/Review Article

\title{
Current efforts for prediction and assessment of natural disasters: Earthquakes, tsunamis, volcanic eruptions, hurricanes, tornados, and floods
}

\author{
J.P. Amezquita-Sanchez ${ }^{\mathrm{a}, *}$, M. Valtierra-Rodriguez ${ }^{\mathrm{a}}$ and H. Adeli ${ }^{\mathrm{b}}$ \\ a. Faculty of Engineering, Departments of Electromechanical, Civil, and Biomedical Engineering. Autonomous University of \\ Queretaro, Campus San Juan del Rio, Moctezuma 249, Col. San Cayetano, 76807, San Juan del Rio, Queretaro, Mexico. \\ b. Department of Civil, Environmental, and Geodetic Engineering, The Ohio State University, 470 Hitchcock Hall, 2070 Neil \\ Avenue, Columbus, OH 43220, U.S.A.
}

Received 22 October 2017; accepted 4 November 2017

\author{
KEYWORDS \\ Natural disasters; \\ Big data; \\ Prediction; \\ Assessment; \\ Earthquakes; \\ Tsunamis; \\ Volcanic eruptions; \\ Hurricanes; \\ Tornadoes; \\ Floods.
}

\begin{abstract}
This article presents a state-of-the-art review of different methods, signal and image processing techniques, and statistical analyses used for prediction and assessment of natural disasters including earthquakes, tsunamis, volcanic eruptions, hurricanes, tornadoes, and floods. Application of the big data paradigm to the aforementioned natural disasters is also discussed. The research for increasingly more sophisticated computational models will continue to achieve more accurate predictions of various natural disasters.
\end{abstract}

(C) 2017 Sharif University of Technology. All rights reserved.

\section{Introduction}

Natural Disasters (NDs) are considered sudden phenomena produced by natural factors of earth causing significant economic and human losses. Earthquakes, tsunamis, volcanic eruptions, hurricanes, tornadoes, and floods are among the most common NDs encountered on earth. They are often abruptly generated, thus limiting action-taking before they occur. Hence, the development of methodologies and systems capable of predicting and assessing both the occurrence possi-

\footnotetext{
*. Corresponding author.

Tel.: +52 (1) 4272741244

E-mail address: jamezquita@uaq.mx (J.P

Amezquita-Sanchez)
}

doi: $10.24200 /$ sci. 2017.4589 bility of NDs and possible magnitude of damage is of paramount importance for the society.

During the last three decades, numerous methods, signal and image processing techniques, and statistical analyses as well as advanced measuring equipment have been introduced to create prediction and assessment systems of damage and vulnerability using the measured data of different NDs. The common thread is the analysis and processing of a large amounts of data. In general, a prediction or assessment system of an ND consists of three main steps: data collection and monitoring, data processing and statistical analysis, and interpretation (Figure 1). Data monitoring can range from a simple sensor with a low sampling frequency to collaborative and non-collaborative networks of sensors that provide huge volumes and different types of data, requiring high performance capabilities for data transmission, storage, and management. As 


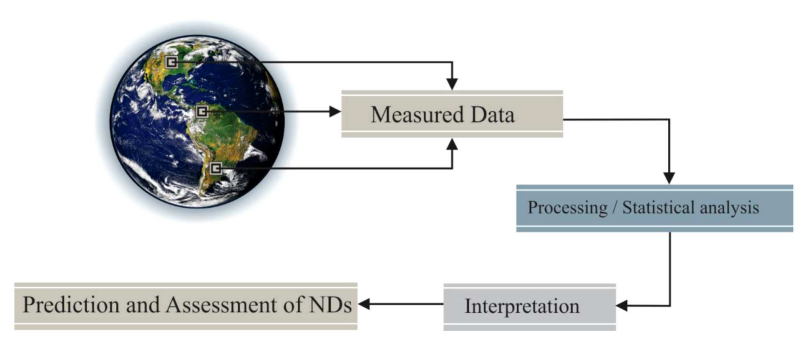

Figure 1. Three main steps in the prediction and assessment system of NDs.

a direct consequence, the processing and analysis of measured data can become demanding and complicated. On the one hand, powerful computers or even a network of them are required and, on the other hand, the application of conventional signal and image processing techniques may be insufficient, requiring advanced and complex methods. From a general point of view, these scenarios, among others, have led to the development and application of approaches within a big data context.

This article presents a state-of-the-art review of different methods, signal and image processing techniques, and statistical analyses used for prediction and assessment of NDs, including earthquakes, tsunamis, volcanic eruptions, hurricanes, tornadoes, and floods. Also, application of big data paradigms to the aforementioned NDs is briefly discussed.

\section{Earthquake prediction}

The term earthquake (EQ) refers to the shaking of the earth surface which is the result of an abrupt release of energy in the earth's lithosphere that creates seismic waves. These waves can produce a great catastrophe depending on their magnitude, epicentral location, and time of occurrence, resulting in significant risk to human life. Panakkat and Adeli [1] presented a stateof-the-art review of research efforts in EQ prediction published in the period from 1990 to 2007. This section presents a review of the efforts to predict earthquakes since 2008, including methods based on animal behavior, changes in water, changes in electrical and magnetic field signals, foreshocks before a major earthquake, and analysis of historical data.

\subsection{Changes in animal behavior prior to an earthquake}

A rudimentary approach to EQ prediction is the observation of animal behavior. Numerous investigations report changes in the behavior of different animals before an EQ. For example, Holland et al. [2] reported that the bat Eptesicus fuscus is capable of perceiving changes in magnetic fields from 1 to $100 \mathrm{nT}$. The authors noted that monitoring the earth magnetic field can be used as a potential precursor for prediction of ND; in particular, EQ. Li et al. [3] monitored 8 mice before, during, and after the 2008 Wenchuan earthquake of magnitude 8.0 in the Wenchuan county of Sichuan province, China. They observed changes in the locomotive activities of the mice 3 days prior to EQ, returning to their normal activities 6 days after the EQ. The authors argued that this phenomenon can be associated to variations produced in the Earth's geomagnetic intensity. Grant and Halliday [4] investigated a population of reproductively active toads (Bufo bufo), which showed sudden changes in their behavior before and after the 2009 L'Aquila earthquake of magnitude 6.3. They stopped spawning 5 days prior to EQ, and then not returning to their normal reproductive behavior until 6 days after the quake ended. The authors associated this behavior with the pre-EQ perturbations produced in the ionosphere, which can be sensed by very low frequency radio sounds. Fidani [5] conducted an exhaustive investigation of the abnormal behaviors of different animals, such as dogs and cows, before the 2009 L'Aquila, Italy, earthquake by asking people to respond to a quiz [6]. Based on the review of the people's responses, the author found that all observed dogs (different sizes and breeds) started to bark about one hour before the main shock and stopped immediately after the main shock. On the other hand, the cows in Cagnano Amiterno and Monticchio produced 20 to $50 \%$ less milk 4 weeks before the EQ; moreover, in Camarda, Italy, they tried to break their chains 5 minutes before EQ. Fidani [5] also observed anomalies in the behavior of other animals such as fish and insects; however, he noted that an additional investigation is necessary in order to determine if the observed behavior is influenced by a geophysical parameter. Similar experiments were presented by Yamauchi et al. [7] who reported an unusual decrease in milk yield of the Holstein cows at Ibaraki, Japan, six days before the 2011 Tohoku, Japan EQ with magnitude of 9.0 , and the decrease in the milk yield continued for four days after EQ. The authors noted the need for additional studies of the relation between milk yield levels in other EQs. Grant et al. [8] performed an image analysis of wild animals in Yanachaga National Park, Peru, based on the observation of their behavior 23 days before the 2011 Contamana, Peru, earthquake of magnitude of 7.0. The authors observed a reduction in the movements of the animals 10 days before the EQ. They attributed this unusual behavior to the pre-EQ perturbations in the ionosphere registered two weeks prior to the EQ, which can be sensed by very low frequency radio sounds.

The aforementioned works reported quantitative data analyses of the abnormal animal behavior prior to large EQs. Nevertheless, a long-term study is necessary to validate the hypotheses of previous works as well as observe the animal behavior under different situations 
such as different EQ magnitudes, epicentral location, among others. To this end, a few studies include longterm observation of data. For example, Berberich et al. [9] performed image analysis of a group of red wood ant mounds known as Formica rufa-group in Eifel, Germany, a seismically active region, during a 3-year period (from January 2009 to December 2012) in order to study their behavior before an EQ. In those 3 years, 10 small EQs of magnitude $<4.0$ occurred within a $40 \mathrm{~km}$ radius. The authors noted that the ants present a well-established daily standard routine amenable to characterization. Based on this assumption, they reported that ants present a change in their behavior a few hours before an EQ, but also suggested additional investigations for EQs of magnitude $>4$.0. Yamauchi et al. [10] studied behavior of cows prior to an EQ over a period of one year. Thirty five EQs of magnitude $>5.5$ were registered during the investigation. The authors found a decrease in the cow milk production about 3 weeks prior to the occurrence of EQ, coinciding with the anomalies produced and measured in ultralow frequency magnetic fields of the lithosphere.

\subsection{Changes in water composition and level}

Numerous studies have focused on analyzing abnormal changes in the chemical composition of water before an EQ, in particular, observing the variation of radon concentration prior to an EQ. For example, Singh et al. [11] studied the radon concentration in groundwater in Banikhet, India during 9 months from December 2006 to September 2007. Seven EQs of magnitude $<5.0$ were registered during the investigation. The authors reported a variation in radon concentration in the water in about 2 weeks and 4 days prior to EQ of magnitudes 5.0 and 2.2, respectively. Similar experiments were performed by Kumar et al. [12] who measured radon concentration in groundwater in Amritsar, India prior to 14 EQs of magnitude $<5.0$ over a period of 20 months. The authors reported a variation in radon concentration in water from 2 weeks to a few hours prior to EQ depending on the magnitude and epicentral location of EQ. Tsunomori and Tanaka [13] reported a gradual increase in the radon concentration of the groundwater at Izu Peninsula, Japan, 3 months before the 2011 Tohoku, Japan, EQ of magnitude 9.0. They also noted that this level of concentration occurred only once in 35 years of observation. Grant et al. [14] reported that the movement of tectonic plates before an EQ generates positive hole electrons (defect electrons on the oxygen anion sublattice of silicate minerals) which produce a range of follow-on reactions when they arrive at the Earth's surface. These reactions cause an air ionization injecting a massive amount of primary positive air ions into lower atmosphere. When these positive air ions interact with a rock-water interface, they contaminate the water drunk by the animals resulting in an increase in their blood serotonin level. The authors mention that this phenomenon is produced a few days before a large EQ.

Changes in water level have been also observed prior to a large EQ. Koizumi et al. [15] reported a decrease in the groundwater level at Dogoonsen, Japan, before the 1946 Nankai, Japan, EQ; however, the time of this phenomenon prior to EQ is not reported. Orihara et al. [16] reported a simultaneous decrease in groundwater level and temperature at Iwate prefecture three months before the 2011 Tohoku, Japan, earthquake of magnitude 9.0. The authors attributed the phenomenon to the pre-seismic crustal deformation.

\subsection{Anomalous electromagnetic field changes}

Earth's electromagnetic (EM) emission is another line of study for EQ prediction. Changes in the earth's EM field have been observed from several hundreds to a few thousand kilometers of the epicenter of the EQ. They occur typically during, yet sometimes prior to, EQ [17]. Different frequency ranges, i.e. very-low or low frequency range (VLF-LF) $(10-50 \mathrm{kHz})$ and ultralow-frequency range (ULF) $(0.001-10 \mathrm{~Hz})$, have been employed to analyze the electromagnetic phenomena, with the ULF range seeming to be the most promising as a precursor of a large EQ [18-21].

Ida et al. [22] presented an analysis of polarization to estimate anomalous changes in geomagnetic ULF signals measured at Kashi station in China during the years 2003-2006. The authors claimed that their analysis is capable of estimating anomalous changes in ULF signals a few hours before an EQ of magnitude 6.1 registered on September 1, 2003 within an epicentral distance of $116 \mathrm{~km}$. Chavez et al. [23] employed the Wavelet Transform (WT) [24] with mother wavelet of Daubechies 1 to analyze the ULF geomagnetic signal produced for 19 EQs in Mexico during the years 20072009 with magnitudes in the range of 5.5 to 6.6. They analyzed signals between 9 hrs before an EQ and 9 hrs afterwards, and concluded that the WT is capable of estimating anomalous changes $8.5 \mathrm{hrs}$ before the main shock with a maximum distance of about $790 \mathrm{~km}$ from the monitoring station. Ohta et al. [25] combined the Fourier transform with a 4th-order Butter filter in order to find anomalies in ULF electromagnetic signals produced by the 2011 Japan EQ of magnitude 9.0. The authors noted the presence of lithospheric ULF radiation 5 days before major EQs.

From a signal processing viewpoint, the ULF electromagnetic signals are very low amplitude and highly non-stationary and noise-contaminated, thus making their analysis suitable to detect anomalies associated with challenges of seismic activity. Chavez et al. [20] used the multiple-signal classification (MUSIC) algorithm, originally developed by Jiang and Adeli [26] for 
health monitoring of structures and damage detection in high-rise buildings, to analyze ULF geomagnetic signals and find pre-seismic anomalies. The MUSIC algorithm is capable of estimating frequencies embedded in high-level noise [27], a characteristic encountered in ULF signals. The results show that the proposal can estimate anomalies in ULF signals from 9 to 4.5 hrs before an EQ within an epicentral distance of 630 to $1974 \mathrm{~km}$ to the recording station. Recently, Amezquita-Sanchez et al. [21] combined the Empirical Mode Decomposition (EMD) and the Box Fractal Dimension (BFD) to analyze geomagnetic ULF signals produced by 3 EQs of magnitude $<6.9$ at Jurquilla, Mexico during the years 2009 and 2010. The EMD method allows eliminating the fluctuation in fractal dimension values produced by noise. The authors concluded that fusion of EMD and BFD can help detect anomalies in ULF signals from 8.5 to 5 hrs before the occurrence of EQs within an epicentral distance of 684 to $2292 \mathrm{~km}$ to the station. Despite these promising results, additional investigation is necessary to rule out other potential causes of anomalies such as solar activity, geomagnetic storm, among others [28].

\subsection{Foreshocks}

Foreshocks are a series of small EQs that precede the occurrence of the main shock. Lucente et al. [29] reported that a large number of foreshocks occurred 6 months before the 2009 L'Aquila, Italy EQ of magnitude 6.3. The analysis shows that 6 foreshocks of magnitude $>3.0$ occurred before the main shock including a foreshock of magnitude 4.0 one week before the main shock. The authors noted that these are mainly produced by changes in the elastic properties of rocks in the fault region, generating the possibility that similar processes can be observed in the preparatory phases of future EQs. Hirose et al. [30] reported that foreshock activities started 2 days before the main shock of the 2011 Honshu, Japan, EQ, with a maximum magnitude of 9.0 within an area of $500 \times 200 \mathrm{~km}$. Similar results have been reported for the 2014 Iquique, Chile, earthquake of magnitude 8.1 [31-32].

Foreshocks occurrence before a large EQ has been considered a promising tool for $\mathrm{EQ}$ prediction. However, only two successful evacuations have been claimed: EQs of 1975 Haicheng, China, and the 1995 Kozani-Grevena, Greece [33]. On the other hand, Bakun et al. [34] showed that the 2004 Parkfield, California, EQ of magnitude 6.0 did not have any foreshocks before the occurrence of EQ, noting that further investigations with different EQs are necessary in order to determine if the foreshocks occurrence can be used as a tool for EQ prediction. To that end, Mignan [35] conducted an exhaustive analysis using 37 papers published from 1982 to 2013 where the foreshocks occurrence before an EQ is claimed. The author concluded that the occurrence of the foreshocks and their magnitude depends mainly on the magnitude of the main shock.

\subsection{EQ prediction based on historical data analysis}

Machine learning and neural network [36-38] techniques have been used in a variety of civil engineering applications [39-42] since the first journal article on the subject was published in 1989 [43]. Bose et al. [44] presented PreSEIS based on a backpropagation neural network (BPNN) [45] for predicting the magnitude and locating the hypocenter of EQs with magnitude less than 7.5 at Marmara region, Istanbul. Panakkat and Adeli [46] proposed a recurrent neural network to predict the time and epicentral location of major EQs in southern California between September 21, 1995 and February 22, 2002 of magnitude $>$ 5.6. Adeli and Panakkat [47] developed a Probabilistic Neural Network (PNN) for EQ magnitude prediction and applied the model to EQ data in southern California between January 1, 1950 and December 13, 1990, complementing the previous work published by authors [48]. Moustra et al. [49] employed a three-layer BPNN to predict the EQ magnitude at Greece using the measured seismic electric signals during a period of 21 years from 1980 to 2001. The authors reported prediction accuracy of $84.01 \%$ for EQs of magnitude $>5.0$.

Martínez-Álvarez et al. [50] explored the use of different seismicity indicators as inputs of a BPNN in order to predict EQs magnitude in Chile and Iberian Peninsulas. Florido et al. [51] combined the $b$-value obtained from seismic time series of the four most active Chilean zones (Talca, Pichilemu, Santiago, and Valparaíso) and $k$-means classification to predict the occurrence of EQs. They reported prediction accuracy of only $70 \%$ for EQs with magnitude $>4.4$, thus concluding the necessity of investigating additional seismic indicators as well as classification algorithms.

To reduce false alarms in an on-site earthquake early warning system, Hsu et al. [52] presented approaches to distinguishing the vibration signals caused by non-seismic events from those due to seismic events using singular spectrum analysis and the Support Vector Machine (SVM) classification algorithm [53-54] and verified them using data collected from the Taiwan strong motion instrumentation program. Recently, Rafiei and Adeli [55] developed a novel seismicity indicator-based earthquake early warning system for forecasting the magnitude and location of an earthquake weeks before its occurrence using a combination of a classification algorithm based on machine learning concepts, a mathematical optimization algorithm, and the patented neural dynamic optimization model of Adeli and Park [56]. The classification algorithm is 
used to find whether or not there is an earthquake in a given time period greater than a predefined magnitude threshold. The optimization algorithm is used to find the location of that earthquake with the maximum probability of occurrence. They investigated four different classification algorithms using earthquake data from southern California. They reported the most accurate results using the recently-developed neural dynamic classification algorithm [57] followed by the enhanced probabilistic model [58].

\section{Tsunami prediction}

A Tsunami is a natural phenomenon consisting of a series of waves produced in the ocean and caused mainly by submarine earthquakes, volcanic eruptions, landslides, and large meteorite impacts. It can devastate cities completely producing enormous economical and human losses. Hence, a methodology capable of predicting the arrival time and wave height of a Tsunami is essential for tsunami-prone areas.

Since the 80s, researchers have attempted tsunami forecasting mostly based on computer simulations with empirical considerations of slip amount, fault width, slip angles, and dip [59-60]. Satake [61-62] combined a Tide Gauge (TG) with geodetic data to generate a tsunami forecasting which required a lot of measurement data from TGs along the coast to be reliable. During the past two decades, a number of methodologies have been proposed in order to predict the occurrence of Tsunamis. Koike et al. [63] employed the WT to forecast a tsunami based on tsunami profile time series with a duration of 90 minutes obtained from a couple of offshore sites. The method takes 2 minutes to predict the tsunami heights. In several areas, the Tsunami waves reach the cost within a few minutes; therefore, the proposed methodology is not practical for those locations. Wei et al. [64] presented an inverse regression method for forecasting tsunami waveform near Hawaii using the water level data of the AlaskaAleutian during 1938 to 1986. Titov et al. [65] proposed a linear regression inversion method for tsunami forecasting based on the analysis of tsunami amplitudes measured by the National Oceanic and Atmospheric Administration Tsunami Warning Center. The proposal was evaluated employing the measured data of the Tsunamis of Kuril Islands, Andreanov Islands, and Rat Islands generated during the years 1994, 1996, and 2003, respectively, demonstrating to be effective in predicting the arrival time, amplitude, and the first tsunami waves. In the subsequent three years, the proposed method was updated with more than 1000 tsunami sources, generating a method suitable for Tsunami forecasting from distant sources [66].

The method proposed by Titov et al. [65] and improved by Wei et al. [66] was demonstrated to be effective for far-field Tsunamis; however, for near-field tsunamis, the proposal is not capable of generating a correct estimation of the arrival time and amplitude of a Tsunami, because the window or arrived time of Tsunami is very small. Tsushima et al. [67-68] presented an inverse method for a near-field tsunami forecasting. Numerical simulations were used to train the model and its efficacy was evaluated using the data produced by pressure sensors located at the bottom of the ocean during the small Tsunami generated during 2003 Off-Fukushima EQ and 1896 Sanriku Tsunami EQ. The method was shown to be capable of estimating 5 min before the arrival of the earliest tsunami waves at the coast. Yasuda and Mase [69] combined the inverse method with Global Positioning System (GPS) buoys to improve the Tsunami prediction time. The authors noted that GPS buoys help increase the duration of observation data and decrease the duration of the tsunami prediction. Following Yasuda and Mase [69], Wei et al. [70] conducted a comprehensive evaluation of the efficacy of the GPS buoys for Tsunami prediction, concluding that the GPS buoys can become an effective tool for near-field tsunami prediction. Tsushima et al. [71] also proposed an algorithm for predicting nearfield Tsunamis where the sea surface height distribution is estimated by means of GPS buoys. The results show that the proposed method can estimate the waves' amplitude 5 min before Tsunami arrivals at the coast. Rigos et al. [72] used a polynomial Radial Basis Function (RBF) neural network to extract the shoreline position from coastal video images.

\section{Volcanic eruptions}

In general terms, volcanoes are considered ruptures of the Earth's crust. A volcanic activity is produced by both the ascent of magma to the Earth's surface and its eruption [73]. During a volcanic eruption, ground deformation and expulsion of magma and superheated gases are observed [74-75]. These consequences have a huge negative impact on the society, as they generate human and economic losses as well as environmental changes [76]. In order to minimize the impact, it is of paramount importance to know where, when, and how they will occur [77]. In this regard, many efforts in research and technology development have been carried out. A paper discussing the objectives of volcanic monitoring and prediction was presented by d'Albe [78]. Robock [79] presented the impacts on climate associated to volcanic eruptions. Sparks [73] reviewed the main developments on volcanic forecasting. Marzocchi and Bebbington [76] presented a review of the probabilistic eruption forecasting (PEF), i.e., estimating the probability and whereabouts of a volcanic eruption, in a complex multi-dimensional time-space-magnitude framework. Wilson et al. [80] 
presented a review of the negative impacts on the infrastructure generated by volcanic hazards. Rouwet et al. [81] presented a summary of non-magmatic unrest processes and potential indicators for volcanic hazards.

Eruption forecasting and volcanic hazard assessment are among the most important tasks in modern volcanology [82]. For these tasks, a large number of methods have been proposed such as a statistical method using Weibull analysis and a non-homogeneous generalized Pareto-Poisson process [83], a mixture of exponentials distributions [84], a Bayesian event tree to estimate volcanic hazard (BET_VH) [85-87], a Bayesian event tree for eruption forecasting [88], the extreme value theory [89], global sensitivity analysis based on Fourier and Sobol approaches [90], wavelet analysis [91], and hazard assessment event tree using a Bayesian inference structure [92], among others. Some of the aforementioned algorithms and methods are applied to large amounts of data provided by cellular neural network architectures [93], wireless sensor networks and Global Positioning Systems (GPS) [94], Geographical Information Systems (GIS) [95-98], advanced videobased systems [99], and a combination of Moderate Resolution Imaging Spectroradiometer (MODIS) and the Advanced Spaceborne Thermal Emission and Reflection Radiometer (ASTER) [91], among others [100].

A detailed description of GIS and their application to natural hazards is presented by Tarolli and Cavalli [101]. Such analysis of data has allowed addressing many applications such as analysis of lava flows [95], discrimination of volcanic ashes according to textures [102], ranking of volcanic threats [103], zonation of volcanic hazards [104], zonation of lava flow [105], analysis of sensitivity to lahar hazards for variations in exposed population [106], forecast of style and size of eruptions [82], pattern recognition of volcanic tremor data [107], management of volcanic crises [108], modelling of volcanic source [90], location of incipient volcanic vents [75], characterization of thermal volcanic activities [91], land-use and contingency planning as risk mitigation strategies [80], and development of volcanic alert systems [109].

The aforementioned applications have been successfully carried out due to two main developments: first, the availability of different sources of volcanic activity data using different sensors and measurement technologies; second, the capability of extracting information from data using advanced computational techniques. Effective evaluation of volcanic activity data can provide valuable information for scientists, civil authorities, and the public about the assessment of different volcano-related issues. For instance, risk assessment is described by d'Albe [78] as a tool for considering three factors: value, vulnerability, and hazard. These factors may be estimated using historical data, current measurements, and predicted data. The assessment of long-term volcanic risk from pyroclastic flows is presented by Alberico et al. [110]. Similar work is presented by Alberico et al. [111] for analyzing explosive eruptions at Ischia Island. Vulnerability assessment for development of vulnerability maps, considering total population, land use, infrastructure, economic units and total vulnerability, is presented by Aceves-Quesada et al. [96]. Pesaresi et al. [97] evaluated the social risk due to volcanic eruptions by considering population density and the number of houses. The importance of an effective management of a volcanic crisis is assessed by De la Cruz-Reyna and Tilling [112]. Faggiano et al. [113] presented a vulnerability assessment of buildings under volcanic activity. The combination of a hazard assessment and a cost-benefit analysis associated with the evacuation of people is carried out by Sandri et al. [86]. Becerril et al. [114] presented a long-term volcanic hazard assessment using past eruptive activities.

While many studies have been performed on prediction of volcanic hazards and assessment of volcanic risks with the goal of minimizing the negative impacts, different volcanic systems present different behaviors. Consequently, the use of a single and generic scheme for predicting their volcanic activity and assessing the associated risk may not be the most appropriate. This requires further research.

\section{Hurricanes}

Hurricanes are strong tropical storms [115]. Landfalling hurricanes are among the costliest and deadliest natural hazards [116-117]. Dangers associated with hurricanes, such as strong winds, torrential rains, storm surges, and flooding, have huge negative impacts on people and property [118]. In order to predict and assess these impacts, different tasks have to be taken into account [119], including social vulnerability studies and modeling of hurricane impacts [120]. Young [121] presented a review of the sea state generated by hurricanes. A number of hurricane evacuation studies have also been carried out [122-123]. Pielke Jr. et al. [124] presented a study of economic impacts associated with past hurricane activities.

Among earlier hurricane prediction researches, Molinari [125] presented an approach based on assimilation of remotely-sensed rainfall rates. A highresolution global model is presented by Krishnamurti et al. [126]. The impact of the hurricane-ocean interaction on the intensity of hurricanes is investigated by Bender and Ginis [127]. The Coupled Boundary Layer Air-Sea Transfer (CBLAST)-Hurricane program is presented by Chen et al. [128]. Zhang et al. [116] combined Doppler radar radial velocity observations with ensemble Kalman filter (EKF). The use of EKF is also presented by Weng et al. [129], Weng and Zhang [117], 
Poterjoy and Zhang [130], Zhang and Weng [131], and Lu et al. [132]. The National Oceanic and Atmospheric Administration (NOAA) is also experimenting with ensemble techniques such as EKF [133]. A statisticaldynamical hurricane forecasting system using the sea surface temperature as predictor is presented by Vecchi et al. [134]. An approach based on three-dimensional variational data assimilation (3DVAR-DA) and an advanced regional prediction system along with a cloud analysis is used for analysis and prediction of a landfalling hurricane [135]. A 3DVAR-DA is also combined with the EKF [136-137]. The use of fourdimensional variational (4DVAR) method is presented by Weng et al. [129].

Bayesian uncertainty approach has been used for a number of civil engineering applications in recent year [138-142]. A consensus model that considers the Bayesian model averaging for seasonal hurricane prediction is presented by Jagger and Elsner [143]. Applications of Observing System Simulation Experiments (OSSEs) on hurricane forecasting are shown by Atlas et al. [144]. NOAA is part of a group that conducts OSSEs related to hurricane activity. Besides, NOAA has also established the Hurricane Forecast Improvement Project (HFIP) [145]. The goals of HFIP are focused on hurricane track, intensity, and storm surge forecasts. NOAA has been also collecting data from many tropical cyclones using dropsondes [146]. Dropsondes have extracted data from eyes and eyewalls of hurricanes, as well as from the surrounding environment. A Cyclone Global Navigation Satellite System has been also presented as a tool for hurricane prediction [147]. Hurricane-induced ocean waves are examined by Chen and Curcic [148].

On the other hand, the prediction and assessment of damages induced by hurricanes have been also reported in literature. Especial attention has been given to civil structures as they are critical for protection during the event and post-event recovery [149]. Pinelli et al. [150] presented a prediction model for wind damage in residential structures. Assessment of risk for low-rise light-frame wood residential constructions is presented by $\mathrm{Li}$ and Ellingwood [151], where uncertainties are introduced in the reliability analysis. Chung et al. [152] presented a vulnerability model to predict damage in structures and economic losses. The building and validation of fragility-curve models for damage risk associated with hurricane winds are presented by Subramanian et al. [153]. The assessment of failures on the building envelope of light-frame wood construction is presented by Grayson et al. [154]. Other social aspects associated with the occurrence of Hurricane have also been reported. For instance, a Bayesian decision model for management of emergency supplies has been presented by Taskin and Lodree [155]. Guikema et al. [156] presented a model for predicting power outages associated with hurricanes. Studies for household evacuation during a hurricane have been also carried out [123].

While important advances have been made for prediction and assessment of hurricanes, including their negative impacts, the understanding of both uncertainty sources and inherent uncertainties that affect the hurricane prediction is still a major concern [157].

\section{Tornadoes}

A tornado can be seen as a rotating narrow column of air that extends to the surface of the earth from a cumulonimbus cloud or, in rare cases, a cumulus cloud [158]. Over the past few decades, efforts at the understanding of the structure and dynamics of tornadoes have been carried out [159]. The findings of research have allowed improvements in prediction and assessment of the negative impacts generated by this kind of natural hazard. Despite remarkable advances, a lot more research is still needed. Universities, research institutions, federal agencies, and private meteorological companies have been working to advance our understanding of tornados. A review of forecast, warning, and response to the tornado problem up to 2000 was presented by Golden and Adams [160]. More recently, a review of research and prediction of tropical cyclone tornadoes was presented by Edwards [161] and tornado intensity estimation was presented by Edwards et al. [162]. Brotzge and Donner [163] also presented a review of current efforts, challenges, and opportunities in the context of tornado forecasting, detection, warning decision, dissemination, and public response.

Desrochers and Donalson [164] presented a mesocyclone-detection algorithm (MDA) for prediction of tornadoes. Marzban and Stumpf [165] proposed a Neural Network (NN) model for tornado prediction using Doppler radar-derived (DVRD) attributes. Measured data are usually the basis for tornado prediction methods, yet the selection of the number of predictors is not a straightforward process. Marzban et al. [166] presented an analysis of the best predictors for tornado prediction. A neural network model can be used for pattern recognition in the data associated with tornados, but the architecture of the NN plays an important role in its performance. Marzban [167] discussed the development of an optimal NN. Trafalis et al. [168-169] presented the application of an SVM for detection of tornadoes. Son and Trafalis [170] presented a detection of tornados using an incremental revised support vector machine with filters with a reduction in the number of support vectors and an increase in the detection rate of tornadoes. Logistic regression is also combined with SVMs in order to improve the performance of classifiers for analyzing imbalanced datasets [171], i.e. datasets 
that have different classes of data, but the number of observations for each class is considerably different. Lakshmanan et al. [172] presented a spatiotemporal approach for integrating least-squares, morphological image processing, fuzzy logic [173], and NNs for prediction of tornadoes.

Liu et al. [174] used WT to detect tornadoes from DVRD data. Integration of the three main soft computing paradigms of NN, Fuggy Logic (FL), and Genetic Algorithm (GA) for solution of complicated pattern recognition problems was advanced in a seminal book by Adeli and Hung [36]. Wang et al. [175] presented a neuro-fuzzy system for tornado prediction based on the integration of tornadic signatures in both velocity and spectral domains. A multiple-Doppler radar analysis for detection and characterization of tornado-like vortices is presented by Potvin et al. [176]. The analysis considers a low-order model that combines a uniform flow, linear shear flow, linear divergence, and Rankine vortex. Multiple Markov boundaries are presented by $\mathrm{Yu}$ et al. [177] in order to identify multiple precursors for tornado forecasting. Sea surface temperature data obtained from both the Gulf of Alaska and the western Caribbean Sea are used by Elsner and Widen [178] to predict the spring tornado activity using a Bayesian statistical model.

The relationship between the tornado size and damage intensity has been a subject of research. Brooks [179] discussed the modeling of path lengths and widths of tornadoes using a Weibull distribution. Research by Eppelbaum [180] indicates that the SunEarth-Moon gravitational/magnetic system has a relationship with the occurrence of tornadoes. A first step towards achieving the goal of tornado warning is the prediction of parent thunderstorms that spawn tornadoes. To that end, the 8 May, 2003 Oklahoma City tornadic supercell and embedded tornadoes were predicted by Xue et al. [181]. A Bayesian framework that obtained the regional characterization of tornado activity in accordance with large-scale climatic processes was presented by Cheng et al. [182].

Studies on the relationship between warnings, false alarms, lead times, human vulnerability, and tornado casualties have also been carried out. Simmons and Sutter [183] examined how the number of casualties, injuries, and fatalities in a tornado event is reduced when warnings are emitted with longer lead times. The impact of false alarms on warnings and casualties in tornadoes is studied by Simmons and Sutter [184]. Simmons and Sutter [185] explored the conditions that generate more negative consequences in a tornado event. In a similar study, Durage et al. [186] carried out a comparison of the detection and warning systems of two countries, i.e. United States and Canada, and pointed to opportunity areas where capabilities in detection systems and warning dissemination methods can be improved. Tornado sirens are commonly used as a warning dissemination method. Mathews et al. [187] presented the modeling of tornado siren sound propagation.

In tornado prediction, long-lead time plays an important role in society as it will improve the emergency response, but many meteorological variables are involved in the process, compromising the longlead tornado forecasting. Besides, different regions may originate different trajectories. Occurrence of multiple tornadoes and severe storms, i.e. a tornado outbreak [161], is also possible which increases the analysis complexity.

\section{Floods}

Due to climate warming, extreme precipitation is expected to be more intense and frequent [188], which may lead to floods and other natural disasters such as landslides. Also, other hydrologic processes, such as snowmelt, can increase the occurrence of floods [189190]. In that context, development of methods for prediction and assessment of floods is important for the scientific community [191]. Improving these methods to minimize negative impacts, such as damage to infrastructure and health of a population, is challenging due to many influencing factors and the uncertainties involved. For example, Ferraris et al. [192] discussed the uncertainties in the prediction of flash floods in the northern Mediterranean environment. Takeuchi [193] described the relationship between flood damage and social impacts. The application of GIS and remote sensing for flood assessment was discussed by Jeyaseelan [194]. Cloke and Pappenberger [195] reviewed the use of Ensemble Prediction Systems (EPS) for flood forecasting. Floods often lead to contamination. Taylor et al. [196] presented a review of flood management for prediction of microbial contamination.

Existence of a measurement infrastructure, e.g. a basin-wide flow measurement infrastructure and the access to flow and rainfall data, allows for improvements in flood forecasting [197]. To that end, remote sensing using specific satellite-based systems has become a promising technique. Hossain [198] described a radar altimetry satellite system for operational flood forecasting. Analysis and description of satellite altimetry as a tool for many hydrological applications, such as flood forecasting, was presented by Hossain et al. [197]. Along with the use of novel technological hardware, advanced computational techniques and methodologies are required for the processing of data. For instance, SAR-based images require manual processing operations, such as threshold selection, for segmentation. Besides, a user has to have a certain expertise in visual interpretation, among other needs. In this regard, image registration [199-200], 
segmentation [201], analysis [202-203], filtering [204], and recognition research [205-207] can be applied to flood prediction. Kussul et al. [208] presented an NN approach to automatic image segmentation. Another application of NN for flood prediction in the River Arno was presented by Campolo et al. [209] where errors of 7 to $15 \%$ for flow rate are reported. Storage cell and Riemann approaches were presented by Villanueva et al. [210]. Damle and Yalcin [211] presented a time series data mining-based approach and applied it to the data collected at the St. Louis gauging station. The application of Genetic Algorithms (GAs), in specific an accelerated GA, for forecasting flood was presented by Jin et al. [212]. Smith et al. [213] presented a data-based mechanistic model to forecast Flash Floods $(\mathrm{FFs})$. FFs is associated with heavy rains that cause rapid flooding in areas susceptible to collecting water. A Bayesian network-based method for finding the dependency patters in data for flood correlation models was presented by Azami et al. [214]. Javadnejad et al. [215] used a GIS-based mapping approach to realtime redelineation of multi-frequency floods.

Porporato and Ridolfi [216] presented a nonlinear model to forecast river flows. Ferraris et al. [192] discussed estimation of hydrographs using a disaggregation scheme that considers large-scale predicted rainfall volumes in specific area of interest. Montaldo et al. [217] described a distributed hydrologic model for flood prediction applied to the Toce alpine basin. Komma et al [218] studied catchment non-linearity and forecast probabilities for ensemble prediction of floods. Prediction of snowmelt floods was presented by Zeinivand and De Smedt [219]. An approach to real-time prediction of floods generated by overtopping failure in natural dams was developed by $\mathrm{Ma}$ and $\mathrm{Fu}$ [220]. Studies of extreme floods were carried by Takeuchi [193] and Wu et al. [188].

From the reviewed studies, it is evident that there are many topics of research related to the study of floods. Once again, different types and sources of data become necessary for development of flood prediction models. In fact, the lack of sufficient data along with the deficiency of data analysis can lead to a catastrophe. For instance, Webster et al. [221] concluded that the floods of Pakistan could have been predicted, reducing their negative consequences. Even when data are available, there are still uncertainties and errors in the prediction of floods [222]. Satellite technology has proven to be a useful source of data for prediction and assessment of flood-related topics, but may be somehow inaccessible in developing countries.

\section{Big data and natural disasters}

Over the past few years, the concept of big data has penetrated many fields of research [223-224]. Although

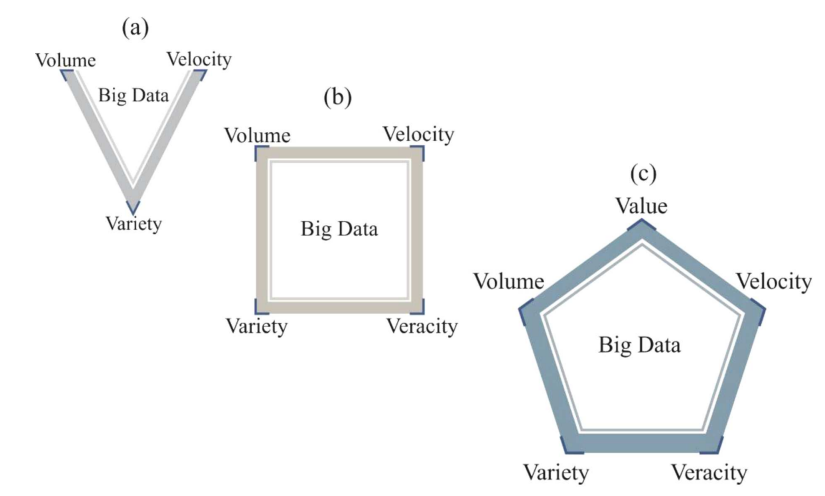

Figure 2. Features of big data: (a) $3 \mathrm{Vs}$, (b) $4 \mathrm{Vs}$, and (c) $5 \mathrm{Vs}$.

the term big data is still not well defined, it is broadly defined in the literature as massive structured or unstructured data volumes that cannot be stored, processed, and analyzed using conventional hardware and software technologies [225-227]. Also, it has been characterized by a simple concept based on a specific number of Vs. Figure 2 shows the evolution of that concept. First, big data was associated with specific complexities referred to as the 3Vs: volume (great volume), velocity (rapid generation), and variety (various types of data) (Figure 2a) [228]. An early definition was introduced by Gantz and Reinsel [229] as follows: "Big data describe a new generation of technologies and architectures, designed to economically extract value from very large volumes of a wide variety of data, by enabling high-velocity capture, discovery, and/or analysis". Based on this definition, a new dimension is added to the concept of big data, veracity, forming the 4 th $\mathrm{V}$ (usefulness of results obtained from data analysis) ( Figure 2(b)). Recently, a new measure of complexity has been added: value, as the 5 th $\mathrm{V}$ (better decision support, research, and operations) (see Figure 2(c)) [227]. All the aforementioned issues involve and generate specific challenges and opportunities for research and technological development in specific scientific areas. Lee and Kang [225] described on-going efforts on geospatial big data. They introduced a three-layer system: geospatial big data integration and management, geospatial big data analytics, and geospatial big data service platform. The use of cloud computing for big geospatial data was presented by Yang et al. [227]. Dhamodaran et al. [230] discussed big data implementation of natural disaster monitoring and alerting system in real-time social network using Hadoop technology and Twitter-based information. Hadoop technology is an open-source Java-based programming framework created for the processing and storage of very large data sets in a distributed computing environment [231]. The idea is to extract from tweets keywords, such as "Earthquake" and "Tsunami", among others, in order to send auto- 
matic alerts to people. Song et al. [232] investigated prediction and simulation of human mobility following natural disasters using big and heterogeneous data that comprise GPS records of 1.6 million users over 3 years and data on EQs that have occurred in Japan. A company named Terra Seismic [233] performed a realtime monitoring of satellite data and environmental factors aiming to predict natural disasters including earthquakes.

Preis et al. [234] discussed the real-time quantification of the digital traces of Hurricane Sandy using use of a photo sharing website, Flickr. Shelton at al. [235] investigated the Twitter activity in the wake of Hurricane Sandy for social geographic analysis with the goal of uncovering the sociospatial dimensions of the big data. Twitter-based information for communication of a volcanic eruption, Indonesia's Mt. Sinabung, was also analyzed by Chatfield and Reddick [236]. A Big Data Assimilation (BDA) project was described by Miyoshi et al. [237] for weather prediction, providing an early warning about natural disasters such as tornadoes and floods, among others. Big data analytics is used for both flood information management [238] and long-lead extreme flood forecasting [239]. Rathore et al. [240] discussed urban planning and building smart cities using the Internet of Things technology and big data analytics. They analyzed datasets of floods to obtain the thresholds for predicting floods and alerting the public.

\section{Conclusions}

During the last three decades, systems capable of predicting and assessing natural disasters have played an important role in society and scientific community because they allow taking preventive measures in order to minimize the negative effects on people and infrastructure. This paper presented an overview of recent methods and developments for predicting and assessing earthquakes, tsunamis, volcanic eruptions, hurricanes, tornadoes, and floods in the past two decades including a few approaches presented in the literature within the context of big data. Despite significant advances, prediction of natural disasters still presents a major challenge to the scientific community due to their complexities and many geophysical, hydrological, and meteorological factors with significant inherent uncertainties.

In recent years, emerging computing paradigms, such as machine learning, including artificial neural networks, fuzzy logic [241-243], genetic algorithms, and support vector machines, have been applied for prediction and assessment of natural disasters. GIS and GPS are also being used [244]. Further, the application of signal processing techniques, such as wavelet transform, Kalman filter, MUSIC, and EMD- based methods, has led to improvements in the extraction of useful information from data. This research will continue to achieve increasingly more accurate predictions.

\section{References}

1. Panakkat, A. and Adeli, H. "Recent efforts in earthquake prediction (1990-2007)", Natural Hazards Review, 9(2), pp. 70-80 (2008).

2. Holland, R.A., Kirschvink, J.L., Doak, T.G. and Wikelski, M. "Bats use magnetite to detect the earth's magnetic field", PLoS One, 3(2), e1676 (6 pages) (2008).

3. Li, Y., Liu, Y., Jiang, Z., Guan, J., Yi, G., Cheng, S. and Wang, Z. "Behavioral change related to Wenchuan devastating earthquake in mice", Bioelectromagnetics, 30(8), pp. 613-620 (2009).

4. Grant, R.A. and Halliday, T. "Predicting the unpredictable; evidence of pre-seismic anticipatory behaviour in the common toad", Journal of Zoology, 281(4), pp. 263-271 (2010).

5. Fidani, C. "Biological anomalies around the 2009 L'aquila earthquake", Animals, 3(3), pp. 693-721 (2013).

6. Fidani, C. "The earthquake lights (EQL) of the 6 April 2009 Aquila earthquake, in Central Italy", Natural Hazards and Earth System Sciences, 10(5), pp. 967-978 (2010).

7. Yamauchi, H., Uchiyama, H., Ohtani, N. and Ohta, M. "Unusual animal behavior preceding the 2011 earthquake off the pacific coast of Tohoku, Japan: a way to predict the approach of large earthquakes", Animals, 4(2), pp. 131-145 (2014).

8. Grant, R.A., Raulin, J.P. and Freund, F.T. "Changes in animal activity prior to a major $(\mathrm{M}=7)$ earthquake in the Peruvian Andes", Physics and Chemistry of the Earth, Parts $A / B / C$, 85, pp. 69-77 (2015).

9. Berberich, G., Berberich, M., Grumpe, A., Wöhler, C. and Schreiber, U. "Early results of three-year monitoring of Red Wood ants' behavioral changes and their possible correlation with earthquake events", Animals, 3(1), pp. 63-84 (2013).

10. Yamauchi, H., Hayakawa, M., Asano, T., Ohtani, N. and Ohta, M. "Statistical evaluations of variations in dairy cows' milk yields as a precursor of earthquakes", Animals, 7(3), 19 (17 pages) (2017).

11. Singh, S., Kumar, A., Bajwa, B.S., Mahajan, S., Kumar, V. and Dhar, S. "Radon monitoring in soil gas and ground water for earthquake prediction studies in North West Himalayas", Terrestrial Atmospheric and Oceanic Science, 21(4), pp. 685-695 (2010).

12. Kumar, A., Walia, V., Singh, S., Bajwa, B.S., Dhar, S. and Yang, T.F. "Earthquake precursory studies at Amritsar Punjab, India using radon measurement techniques", International Journal of Physical Sciences, 7(42), pp. 5669-5677 (2013). 
13. Tsunomori, F. and Tanaka, H. "Anomalous change of groundwater radon concentration monitored at Nakaizu well in 2011", Radiation Measurements, 60, pp. 35-41 (2014).

14. Grant, R.A., Halliday, T., Balderer, W.P., Leuenberger, F., Newcomer, M., Cyr, G. and Freund, F.T. "Ground water chemistry changes before major earthquakes and possible effects on animals", International Journal of Environmental Research and Public Health, 8(6), pp. 1936-1956 (2011).

15. Koizumi, N., Takahashi, M., Matsumoto, N., Sato, T., Ohtani, R. and Kitagawa, Y. "Hydrological research for earthquake prediction: trial for detection of preseismic crustal deformation from groundwater changes", Journal of the Seismological Society of Japan, 58(3), pp. 247-258 (2005).

16. Orihara, Y., Kamogawa, M. and Nagao, T. "Preseismic changes of the level and temperature of confined groundwater related to the 2011 Tohoku earthquake", Scientific Reports, 4, 6907 (6 pages) (2014).

17. Molchanov, O.A. and Hayakawa, M. "Seismoelectromagnetics and related phenomena: History and latest results", Terrapub, 190 (182 pages) (2008).

18. Kumar, N., Rawat, G., Choubey, V.M. and Hazarika, D. "Earthquake precursory research in western Himalaya based on the multi-parametric geophysical observatory data", Acta Geophysica, 61(4), pp. 977999 (2013).

19. Rawat, G. "Characteristic ULF band magnetic field variations at MPGO, Ghuttu for the 20 June 2011 earthquake in Garhwal Himalaya", Current Science, 106(1), pp. 88-93 (2014).

20. Chavez, O., Amezquita-Sanchez, J.P., ValtierraRodriguez, M., Cruz-Abeyro, J.A., Kotsarenko, A., Millan-Almaraz, J.R., Dominguez-Gonzalez, A. and Rojas, E. "Novel ST-MUSIC-based spectral analysis for detection of ULF geomagnetic signals anomalies associated with seismic events in Mexico", Geomatics, Natural Hazards and Risk, 7(3), pp. 1162-1174 (2016).

21. Amezquita-Sanchez, J.P., Chavez-Alegria, O., Valrierra-Rodriguez, M., Cruz-Abeyro, J.A.L., Millan-Almaraz, J.R. and Dominguez-Gonzalez, A. "Detection of ULF geomagnetic anomalies associated to seismic activity using EMD method and fractal dimension theory", IEEE Latin America Transactions, 15(2), pp. 197-205 (2017).

22. Ida, Y., Yang, D., Li, Q., Sun, H. and Hayakawa, M. "Detection of ULF electromagnetic emissions as a precursor to an earthquake in China with an improved polarization analysis", Natural Hazards and Earth System Science, 8(4), pp. 775-777 (2008).

23. Chavez, O., Millan-Almaraz, J.R., Pérez-Enríquez, R., Arzate-Flores, J.A., Kotsarenko, A., CruzAbeyro, J.A. and Rojas, E. "Detection of ULF geomagnetic signals associated with seismic events in central Mexico using discrete wavelet transform", Natural Hazards and Earth System Science, 10(12), pp. 2557-2564 (2010).
24. Alhassan, A., White, D.J. and De Brabanter, K. "Wavelet filter design for pavement roughness analysis", Computer-Aided Civil and Infrastructure Engineering, 31(12), pp. 907-920 (2016).

25. Ohta, K., Izutsu, J., Schekotov, A. and Hayakawa, M. "The ULF/ELF electromagnetic radiation before the 11 March 2011 Japanese earthquake", Radio Science, 48(5), pp. 589-596 (2013).

26. Jiang, X. and Adeli, H. "Pseudospectra, MUSIC, and dynamic wavelet neural network for damage detection of highrise buildings", International Journal for $\mathrm{Nu}$ merical Methods in Engineering, 71(5), pp. 606-629 (2007).

27. Amezquita-Sanchez, J.P. and Adeli, H. "A new MUSIC-Empirical wavelet transform methodology for time-frequency analysis of noisy nonlinear and nonstationary signals", Digital Signal Processing, 45, pp. 55-68 (2015).

28. Masci, F. and Thomas, J.N. "Are there new findings in the search for ULF magnetic precursors to earthquakes?", Journal of Geophysical Research: Space Physics, 120(12), pp. 10289-10304 (2015).

29. Lucente, F.P., De Gori, P., Margheriti, L., Piccinini, D., Di Bona, M., Chiarabba, C. and Agostinetti, N.P. "Temporal variation of seismic velocity and anisotropy before the 2009 MW 6.3 L'Aquila earthquake, Italy", Geology, 38(11), pp. 1015-1018 (2010).

30. Hirose, F., Miyaoka, K., Hayashimoto, N., Yamazaki, T. and Nakamura, M. "Outline of the 2011 off the Pacific coast of Tohoku earthquake (Mw 9.0)seismicity: foreshocks, mainshock, aftershocks, and induced activity", Earth, Planets and Space, 63(7), pp. 513-518 (2011).

31. Brodsky, E.E. and Lay, T. "Recognizing foreshocks from the 1 April 2014 Chile earthquake", Science, 344(6185), pp. 700-702 (2014).

32. Ruiz, S., Metois, M., Fuenzalida, A., Ruiz, J., Leyton, F., Grandin, R. and Campos, J. "Intense foreshocks and a slow slip event preceded the 2014 Iquique $\mathrm{Mw}$ 8.1 earthquake", Science, 345(6201), pp. 1165-1169 (2014).

33. Wang, K., Chen, Q.F., Sun, S. and Wang, A. "Predicting the 1975 Haicheng earthquake", Bulletin of the Seismological Society of America, 96(3), pp. 757-795 (2006).

34. Bakun, W.H., Aagaard, B., Dost, B., Ellsworth, W.L., Hardebeck, J.L., Harris, R.A. and Michael, A.J. "Implications for prediction and hazard assessment from the 2004 Parkfield earthquake", Nature, 437(7061), pp. 969-974 (2005).

35. Mignan, A. "The debate on the prognostic value of earthquake foreshocks: A meta-analysis", Scientific Reports, 4, pp. 1-5 (2014).

36. Adeli, H. and Hung, S.L., Machine Learning - Neural Networks, Genetic Algorithms, and Fuzzy Systems, John Wiley and Sons, New York (1995). 
37. Siddique, N. and Adeli, H., Computational Intelligence-Synergies of Fuzzy Logic, Neural Networks and Evolutionary Computing, Wiley, West Sussex, United Kingdom (512 pages) (2013).

38. Palomo, E.J. and Lopez-Rubio, E. "Learning topologies with the growing neural forest", International Journal of Neural Systems, 26(3), 1650019 (21 page) (2016).

39. Dai, H., Wang, W. and Zhang, H. "A multiwavelet neural network-based response surface method for structural reliability analysis", Computer-Aided Civil and Infrastructure Engineering, 30(2), pp. 151-162 (2015).

40. Mu, H.Q. and Yuen, K.V. "Ground motion prediction equation development by heterogeneous Bayesian learning", Computer-Aided Civil and Infrastructure Engineering, 31(10), pp. 761-776 (2016).

41. Dai, H. "A wavelet support vector machine-based neural network meta model for structural reliability assessment", Computer-Aided Civil and Infrastructure Engineering, 32(4), pp. 344-357 (2017).

42. Cha, Y.J., Choi, W. and Buyukozturk, O. "Deep learning-based crack damage detection using convolutional neural networks", Computer-Aided Civil and Infrastructure Engineering, 32(5), pp. 361-378 (2017).

43. Adeli, H. and Yeh, C. "Perceptron learning in engineering design", Microcomputers in Civil Engineering, 4(4), pp. 247-256 (1989).

44. Bose, M., Wenzel, F. and Erdik, M. "PreSEIS: A neural network-based approach to earthquake early warning for finite faults", Bulletin of the Seismological Society of America, 98(1), pp. 366-382 (2008).

45. Hung, S.L. and Adeli, H. "Object-oriented back propagation and its application to structural design", Neurocomputing, 6(1), pp. 45-55 (1994).

46. Panakkat, A. and Adeli, H. "Recurrent neural network for approximate earthquake time and location prediction using multiple seismicity indicators", Computer-Aided Civil and Infrastructure Engineering, 24(4), pp. 280-292 (2009).

47. Adeli, H. and Panakkat, A. "A probabilistic neural network for earthquake magnitude prediction", $\mathrm{Neu}$ ral Networks, 22(7), pp. 1018-1024 (2009).

48. Panakkat, A. and Adeli, H. "Neural network models for earthquake magnitude prediction using multiple seismicity indicators", International Journal of Neural Systems, 17(01), pp. 13-33 (2007).

49. Moustra, M., Avraamides, M. and Christodoulou, C. "Artificial neural networks for earthquake prediction using time series magnitude data or seismic electric signals", Expert Systems with Applications, 38(12), pp. $15032-15039$ (2011).

50. Martínez-Álvarez, F., Reyes, J., Morales-Esteban, A. and Rubio-Escudero, C. "Determining the best set of seismicity indicators to predict earthquakes. Two case studies: Chile and the Iberian Peninsula", Knowledge-Based Systems, 50, pp. 198-210 (2013).
51. Florido, E., Martínez-Álvarez, F., Morales-Esteban, A., Reyes, J. and Aznarte-Mellado, J.L. "Detecting precursory patterns to enhance earthquake prediction in Chile", Computers \& Geosciences, 76, pp. 112-120 (2015).

52. Hsu, T.Y., Wu, R.T. and Chang, K.C. "Two novel approaches to reduce false alarm due to non-earthquake events for on-site earthquake early warning system", Computer-Aided Civil and Infrastructure Engineering, 31, pp. 535-549 (2016).

53. Chou, J.S. and Pham, A.D. "Smart artificial firefly colony-based support vector regression for enhanced forecasting in civil engineering", Computer-Aided Civil and Infrastructure Engineering, 30(9), pp. 715732 (2015).

54. Castillo, E., Peteiro-Barral, D., Guijarro Berdinas, B. and Fontenla-Romero, O. "Distributed one-class support vector machine", International Journal of Neural Systems, 25(7), 1550029 (17 pages) (2015).

55. Rafiei, M.H. and Adeli, H. "NEEWS: A novel earthquake early warning system using neural dynamic classification", Soil Dynamics and Earthquake Engineering, 100, pp. 417-427 (2017).

56. Adeli, H. and Park, H.S. "A neural dynamics model for structural optimization-theory", Computers \& Structures, 57(3), pp. 383-390 (1995).

57. Rafiei, M.H. and Adeli, H. "A new neural dynamic classification algorithm", IEEE Transactions on $\mathrm{Neu}$ ral Networks and Learning Systems, 28(12), pp. 1-10 (2017).

58. Ahmadlou, M. and Adeli, H. "Enhanced probabilistic neural network with local decision circles: A robust classifier", Integrated Computer-Aided Engineering, 17(3), pp. 197-210 (2010).

59. Izutani, Y. and Hirasawa, T. "Rapid estimation of fault parameters for near-field tsunami warning", Natural Disaster Science, 9(1), pp. 99-113 (1987).

60. Shuto, N., Goto, C. and Imamura, F. "Numerical simulation as a means of warning for near field tsunamis", Coastal Engineering in Japan, 33(2), pp. 173-193 (1990).

61. Satake, K. "Heterogeneous fault motion of large submarine earthquakes: The 1968 Tokachi-oki and 1983 Japan sea earthquakes", Journal of Geophysical Research, 94(B5), pp. 5627-5636 (1989).

62. Satake, K. "Depth distribution of coseismic slip along the Nankai trough, Japan", Journal of Geophysical Research, 98(B3), pp. 4553-4565 (1993).

63. Koike, N., Kawata, Y. and Imamura, F. "Far-field tsunami potential and a real-time forecast system for the Pacific using the inversion method", Natural Hazards, 29(3), pp. 425-436 (2003).

64. Wei, Y., Cheung, K.F., Curtis, G.D. and McCreery, C.S. "Inverse algorithm for tsunami forecasts", Journal of Waterway, Port, Coastal, and Ocean Engineering, 129(2), pp. 60-69 (2003). 
65. Titov, V.V., Gonzalez, F.I., Bernard, E.N., Eble, M.C., Mofjeld, H.O., Newman, J.C. and Venturato, A.J. "Real-time tsunami forecasting: challenges and solutions", Natural Hazards, 35(1), pp. 35-41 (2005).

66. Wei, Y., Bernard, E.N., Tang, L., Weiss, R., Titov, V.V., Moore, C. and Kănoğlu, U. "Real-time experimental forecast of the Peruvian tsunami of August 2007 for US coastlines", Geophysical Research Letters, 35(4), L04609 (7 pages) (2008).

67. Tsushima, H., Hino, R., Fujimoto, H., Tanioka, Y. and Imamura, F. "Near-field tsunami forecasting from cabled ocean bottom pressure data", Journal of Geophysical Research: Solid Earth, 114(B6), B06309 (20 pages) (2009).

68. Tsushima, H., Hino, R., Tanioka, Y., Imamura, F. and Fujimoto, H. "Tsunami waveform inversion incorporating permanent seafloor deformation and its application to tsunami forecasting", Journal of Geophysical Research: Solid Earth, 117(B3), B03311 (20 pages) (2012)

69. Yasuda, T. and Mase, H. "Real-time tsunami prediction by inversion method using offshore observed GPS buoy data: Nankaido", Journal of Waterway, Port, Coastal, and Ocean Engineering, 139(3), pp. 221-231 (2012).

70. Wei, Y., Newman, A.V., Hayes, G.P., Titov, V.V. and Tang, L. "Tsunami forecast by joint inversion of realtime tsunami waveforms and seismic or GPS data: application to the Tohoku 2011 tsunami", Pure and Applied Geophysics, 171(12), pp. 3281-3305 (2014).

71. Tsushima, H., Hino, R., Ohta, Y., Iinuma, T. and Miura, S. "tFISH/RAPiD: Rapid improvement of near-field tsunami forecasting based on offshore tsunami data by incorporating onshore GNSS data", Geophysical Research Letters, 41(10), pp. 3390-3397 (2014).

72. Rigos, A., Tsekouras, G.E., Vousdoukas, M.I., Chatzipavlis, A. and Velegrakis, A.F. "A Chebyshev polynomial radial basis function neural network for automated shoreline extraction from coastal imagery", Integrated Computer-Aided Engineering, 23(2), pp. 141-160 (2016).

73. Sparks, R.S.J. "Forecasting volcanic eruptions", Earth and Planetary Science Letters, 210(1), pp. 1-15 (2003).

74. Brenguier, F., Shapiro, N. M., Campillo, M., Ferrazzini, V., Duputel, Z., Coutant, O. and Nercessian, A. "Towards forecasting volcanic eruptions using seismic noise", Nature Geoscience, 1(2), pp. 126-130 (2008).

75. Junek, W.N., Jones, W.L. and Woods, M.T. "Locating incipient volcanic vents using multidisciplinary remote sensing data and source modeling information", IEEE Geoscience and Remote Sensing Letters, 10(1), pp. 140-144 (2013).

76. Marzocchi, W. and Bebbington, M.S. "Probabilistic eruption forecasting at short and long time scales", Bulletin of Volcanology, 74(8), pp. 1777-1805 (2012).
77. Selva, J., Orsi, G., Di Vito, M.A., Marzocchi, W. and Sandri, L. "Probability hazard map for future vent opening at the Campi Flegrei caldera, Italy", Bulletin of Volcanology, 74(2), pp. 497-510 (2012).

78. d'Albe, E.F. "Objectives of volcanic monitoring and prediction", Journal of the Geological Society, 136(3), pp. 321-326 (1979).

79. Robock, A. "Volcanic eruptions and climate", Reviews of Geophysics, 38(2), pp. 191-219 (2000).

80. Wilson, G., Wilson, T.M., Deligne, N.I. and Cole, J.W. "Volcanic hazard impacts to critical infrastructure: A review", Journal of Volcanology and Geothermal Research, 286, pp. 148-182 (2014).

81. Rouwet, D., Sandri, L., Marzocchi, W., Gottsmann, J., Selva, J., Tonini, R. and Papale, P. "Recognizing and tracking volcanic hazards related to nonmagmatic unrest: a review", Journal of Applied Volcanology, 3(17), (17 pages) (2014).

82. Orsi, G., Di Vito, M.A., Selva, J. and Marzocchi, W. "Long-term forecast of eruption style and size at Campi Flegrei caldera (Italy)", Earth and Planetary Science Letters, 287(1), pp. 265-276 (2009).

83. Mendoza-Rosas, A.T. and De la Cruz-Reyna, S. "A statistical method linking geological and historical eruption time series for volcanic hazard estimations: applications to active polygenetic volcanoes", Journal of Volcanology and Geothermal Research, 176(2), pp. 277-290 (2008).

84. Mendoza-Rosas, A.T. and De la Cruz-Reyna, S. "A mixture of exponentials distribution for a simple and precise assessment of the volcanic hazard", Natural Hazards and Earth System Sciences, 9(2), pp. 425431 (2009).

85. Marzocchi, W., Sandri, L. and Selva, J. "BET_VH: a probabilistic tool for long-term volcanic hazard assessment", Bulletin of Volcanology, 72(6), pp. 705716 (2010).

86. Sandri, L., Jolly, G., Lindsay, J., Howe, T. and Marzocchi, W. "Combining long-and short-term probabilistic volcanic hazard assessment with cost-benefit analysis to support decision making in a volcanic crisis from the Auckland volcanic field", New Zealand. Bulletin of Volcanology, 74(3), pp. 705-723 (2012).

87. Sandri, L., Thouret, J.C., Constantinescu, R., Biass, S. and Tonini, R. "Long-term multi-hazard assessment for El Misti volcano (Peru)", Bulletin of Volcanology, 76(2), 771 (26 pages) (2014).

88. Lindsay, J., Marzocchi, W., Jolly, G., Constantinescu, R., Selva, J. and Sandri, L. "Towards realtime eruption forecasting in the Auckland volcanic field: application of BET EF during the New Zealand national disaster exercise 'Ruaumoko"', Bulletin of Volcanology, 72(2), pp. 185-204 (2010).

89. Sobradelo, R., Martí, J., Mendoza-Rosas, A.T. and Gómez, G. "Volcanic hazard assessment for the Canary islands (Spain) using extreme value theory", Natural Hazards and Earth System Sciences, 11(10), pp. 2741-2753 (2011). 
90. Cannavó, F. "Sensitivity analysis for volcanic source modeling quality assessment and model selection", Computers \& Geosciences, 44, pp. 52-59 (2012).

91. Murphy, S.W., Wright, R., Oppenheimer, C. and Souza-Filho, C.R. "MODIS and ASTER synergy for characterizing thermal volcanic activity", Remote Sensing of Environment, 131, pp. 195-205 (2013).

92. Sobradelo, R., Bartolini, S. and Martí, J. "HASSET: a probability event tree tool to evaluate future volcanic scenarios using Bayesian inference", Bulletin of Volcanology, 76(1), 770 (15 pages) (2014).

93. Bertucco, L., Coltelli, M., Nunnari, G. and Occhipinti, L. "Cellular neural networks for real-time monitoring of volcanic activity", Computers \& Geosciences, 25(2), pp. 101-117 (1999).

94. Werner-Allen, G., Johnson, J., Ruiz, M., Lees, J. and Welsh, M. "Monitoring volcanic eruptions with a wireless sensor network", Proceedings of the Second IEEE European Workshop on Wireless Sensor Networks, Istanbul, Turkey, pp. 108-120 (2005)

95. Behncke, B., Neri, M. and Nagay, A. "Lava flow hazard at Mount Etna (Italy): new data from a GISbased study", Geological Society of America Special Papers, 396, pp. 189-208 (2005).

96. Aceves-Quesada, J.F., Díaz-Salgado, J. and LópezBlanco, J. "Vulnerability assessment in a volcanic risk evaluation in Central Mexico through a multi-criteriaGIS approach", Natural Hazards, 40(2), pp. 339-356 (2007).

97. Pesaresi, C., Marta, M., Palagiano, C. and Scandone, R. "The evaluation of "social risk" due to volcanic eruptions of Vesuvius", Natural Hazards, 47(2), pp. 229-243 (2008).

98. Marrero, J.M., García, A., Llinares, A., De la CruzReyna, S., Ramos, S. and Ortiz, R. "Virtual tools for volcanic crisis management, and evacuation decision support: applications to El Chichón volcano (Chiapas, México)", Natural Hazards, 68(2), pp. 955-980 (2013).

99. Andò, B. and Pecora, E. "An advanced video-based system for monitoring active volcanoes", Computers \& Geosciences, 32(1), pp. 85-91 (2006).

100. Andò, B. "Let's measure volcanic phenomena", IEEE Instrumentation \& Measurement Magazine, 5(4), pp. 65-70 (2002).

101. Tarolli, P. and Cavalli, M. "Geographic information systems (GIS) and natural hazards", Encyclopedia of Natural Hazrds, Springer, pp. 378-385 (2013).

102. Ersoy, O., Chinga, G., Aydar, E., Gourgaud, A., Cubukcu, H.E. and Ulusoy, I. "Texture discrimination of volcanic ashes from different fragmentation mechanisms: A case study, Mount Nemrut stratovolcano, eastern Turkey", Computers \& Geosciences, 32(7), pp. 936-946 (2006).

103. Ewert, J.W. "System for ranking relative threats of US volcanoes", Natural Hazards Review, 8(4), pp. 112-124 (2007).
104. Quesada, J.F.A., Martin Del Pozzo, A.L. and Blanco, J.L. "Volcanic hazards zonation of the Nevado de Toluca Volcano, Central Mexico", Natural Hazards, 41(1), pp. 159-180 (2007).

105. Bonne, K., Kervyn, M., Cascone, L., Njome, S., Van Ranst, E., Suh, E., Ayonghe, S., Jacobs, P. and Ernst, G. "A new approach to assess long-term lava flow hazard and risk using GIS and low-cost remote sensing: the case of Mount Cameroon, West Africa", International Journal of Remote Sensing, 29(22), pp. 6539-6564 (2008).

106. Wood, N. and Soulard, C. "Variations in population exposure and sensitivity to lahar hazards from Mount Rainier, Washington", Journal of Volcanology and Geothermal Research, 188(4), pp. 367-378 (2009).

107. Messina, A. and Langer, H. "Pattern recognition of volcanic tremor data on Mt. Etna (Italy) with KKAnalysis-A software program for unsupervised classification", Computers \& Geosciences, 37(7), pp. 953-961 (2011).

108. Marzocchi, W., Newhall, C. and Woo, G. "The scientific management of volcanic crises", Journal of Volcanology and Geothermal Research, 247, pp. 181189 (2012).

109. Garcia, A., Berrocoso, M., Marrero, J.M., FernandezRos, A., Prates, G., De la Cruz-Reyna, S. and Ortiz, R. "Volcanic alert system (VAS) developed during the 2011-2014 El Hierro (Canary Islands) volcanic process", Bulletin of Volcanology, 76(825), pp. 1-13 (2014).

110. Alberico, I., Lirer, L., Petrosino, P. and Scandone, R. "A methodology for the evaluation of long-term volcanic risk from pyroclastic flows in Campi Flegrei (Italy)", Journal of Volcanology and Geothermal Research, 116(1), pp. 63-78 (2002).

111. Alberico, I., Lirer, L., Petrosino, P. and Scandone, R. "Volcanic hazard and risk assessment from pyroclastic flows at Ischia island (southern Italy)", Journal of Volcanology and Geothermal Research, 171(1), pp. 118-136 (2008).

112. De la Cruz-Reyna, S. and Tilling, R.I. "Scientific and public responses to the ongoing volcanic crisis at Popocatépetl Volcano, Mexico: importance of an effective hazards-warning system", Journal of Volcanology and Geothermal Research, 170(1), pp. 121134 (2008).

113. Faggiano, B., Formisano, A., De Gregorio, D., De Lucia, T. and Mazzolani, F.M. "A quick level methodology for the volcanic vulnerability assessment of buildings", Applied Mechanics and Materials, 82, pp. 639-644 (2011).

114. Becerril, L., Bartolini, S., Sobradelo, R., Martí, J., Morales, J.M. and Galindo, I. "Long-term volcanic hazard assessment on El Hierro (Canary Islands)", Natural Hazards and Earth System Sciences, 14(7), pp. 1853-1870 (2014). 
115. Zhang, F. "The future of hurricane prediction", Computing in Science \& Engineering, 13(1), pp. 9$12(2011)$.

116. Zhang, F., Weng, Y., Sippel, J.A., Meng, Z. and Bishop, C.H. "Cloud-resolving hurricane initialization and prediction through assimilation of Doppler radar observations with an ensemble Kalman filter", Monthly Weather Review, 137(7), pp. 2105-2125 (2009).

117. Weng, Y. and Zhang, F. "Assimilating airborne Doppler radar observations with an ensemble Kalman filter for convection-permitting hurricane initialization and prediction: Katrina", Monthly Weather Review, 140(3), pp. 841-859 (2012).

118. Elsner, J.B. and Jagger, T.H. "Prediction models for annual US hurricane counts", Journal of Climate, 19 (12), pp. 2935-2952 (2006).

119. Simpson, R.H. "Hurricane prediction: progress and problem areas", Science, 181(4103), pp. 899-907 (1973).

120. Burton, C.G. "Social vulnerability and hurricane impact modeling", Natural Hazards Review, 11(2), pp. 58-68 (2010).

121. Young, I.R. "A review of the sea state generated by hurricanes", Marine Structures, 16(3), pp. 201-218 (2003).

122. Urbina, E. and Wolshon, B. "National review of hurricane evacuation plans and policies: a comparison and contrast of state practices", Transportation Research Part A: Policy and Practice, 37(3), pp. 257275 (2003).

123. Huang, S.K., Lindell, M.K. and Prater, C.S. "Who leaves and who stays? A review and statistical metaanalysis of hurricane evacuation studies", Environment and Behavior, 48(8), pp. 991-1029 (2016).

124. Pielke Jr, R.A., Gratz, J., Landsea, C.W., Collins, D., Saunders, M.A. and Musulin, R. "Normalized hurricane damage in the United States: 1900-2005", Natural Hazards Review, 9(1), pp. 29-42 (2008).

125. Molinari, J. "Numerical hurricane prediction using assimilation of remotely-sensed rainfall rates", Monthly Weather Review, 110(6), pp. 553-571 (1982).

126. Krishnamurti, T.N., Oosterhof, D. and Dignon, N. "Hurricane prediction with a high resolution global model", Monthly Weather Review, 117(3), pp. 631669 (1989).

127. Bender, M.A. and Ginis, I. "Real-case simulations of hurricane-ocean interaction using a high-resolution coupled model: Effects on hurricane intensity", Monthly Weather Review, 128(4), pp. 917-946 (2000).

128. Chen, S.S., Zhao, W., Donelan, M.A., Price, J.F. and Walsh, E.J. "The CBLAST-hurricane program and the next-generation fully coupled atmospherewave-ocean models for hurricane research and prediction", Bulletin of the American Meteorological Society, 88(3), pp. 311-317 (2007).
129. Weng, Y., Zhang, M. and Zhang, F. "Advanced data assimilation for cloud-resolving hurricane initialization and prediction", Computing in Science \& Engineering, 13(1), pp. 40-49 (2011).

130. Poterjoy, J. and Zhang, F. "Predictability and genesis of Hurricane Karl (2010) examined through the EnKF assimilation of field observations collected during PREDICT", Journal of the Atmospheric Sciences, 71(4), pp. 1260-1275 (2014).

131. Zhang, F. and Weng, Y. "Predicting hurricane intensity and associated hazards: A five-year realtime forecast experiment with assimilation of airborne Doppler radar observations", Bulletin of the American Meteorological Society, 96(1), pp. 25-33 (2015).

132. Lu, X., Wang, X., Li, Y., Tong, M. and Ma, X. "GSIbased ensemble-variational hybrid data assimilation for HWRF for hurricane initialization and prediction: impact of various error covariances for airborne radar observation assimilation", Quarterly Journal of the Royal Meteorological Society, 143(702), pp. 223-239 (2016).

133. Hamill, T.M., Brennan, M.J., Brown, B., DeMaria, M., Rappaport, E.N. and Toth, Z. "NOAA's future ensemble-based hurricane forecast products", Bulletin of the American Meteorological Society, 93(2), pp. 209-220 (2012).

134. Vecchi, G.A., Zhao, M., Wang, H., Villarini, G., Rosati, A., Kumar, A., Held, I.M. and Gudgel, R. "Statistical-dynamical predictions of seasonal North Atlantic hurricane activity", Monthly Weather Review, 139(4), pp. 1070-1082 (2011).

135. Zhao, K. and Xue, M. "Assimilation of coastal Doppler radar data with the ARPS 3DVAR and cloud analysis for the prediction of Hurricane Ike (2008)", Geophysical Research Letters, 36(12), pp. 1-6 (2009).

136. Wang, X. "Application of the WRF hybrid ETKF3DVAR data assimilation system for hurricane track forecasts", Weather and Forecasting, 26(6), pp. 868884 (2011).

137. Li, Y., Wang, X. and Xue, M. "Assimilation of radar radial velocity data with the WRF hybrid ensemble3DVAR system for the prediction of Hurricane Ike (2008)", Monthly Weather Review, 140(11), pp. 35073524 (2012).

138. Wang, H., Yajima, A., Liang, R.Y. and CastanedaLopez, H. "Bayesian modeling of external corrosion in underground pipelines based on the integration of Markov chain Monte Carlo techniques and clustered inspection data", Computer-Aided Civil and Infrastructure Engineering, 30(4), pp. 300-316 (2015).

139. Sun, H. and Betti, R. "A hybrid optimization algorithm with Bayesian inference for probabilistic model updating", Computer-Aided Civil and Infrastructure Engineering, 30(8), pp. 602-619 (2015).

140. Castillo, A., Calviño, A., Grande, Z., SánchezCambronero, S., Gallego, I., Rivas, A. and Menéndez, J.A. "A Markovian-Bayesian network for risk analysis 
of high speed and conventional railway lines integrating human errors", Computer-Aided Civil and Infrastructure Engineering, 31(3), pp. 193-218 (2016).

141. Castillo, E., Grande, Z. and Calviño, A. "Bayesian networks-based probabilistic safety analysis for railway lines", Computer-Aided Civil and Infrastructure Engineering, 31(9), pp. 681-700 (2016).

142. Castillo, E., Grande, Z., Mora, E., Xu, X. and Lo, H.K. "proactive, backward analysis and learning in road probabilistic Bayesian network models", Computer-Aided Civil and Infrastructure Engineering, 32(10), pp. 820-835 (2017).

143. Jagger, T.H. and Elsner, J.B. "A consensus model for seasonal hurricane prediction", Journal of Climate, 23(22), pp. 6090-6099 (2010).

144. Atlas, R., Bucci, L., Annane, B., Hoffman, R. and Murillo, S. "Observing system simulation experiments to assess the potential impact of new observing systems on hurricane forecasting", Marine Technology Society Journal, 49(6), pp. 140-148 (2015).

145. Gall, R., Franklin, J., Marks, F., Rappaport, E.N. and Toepfer, F. "The hurricane forecast improvement project", Bulletin of the American Meteorological Society, 94(3), pp. 329-343 (2013).

146. Wang, J., Young, K., Hock, T., Lauritsen, D., Behringer, D., Black, M., Black, P.G., Franklin, J., Halverson, J., Molinari, J., Nguyen, L., Reale, T., Smith, J., Sun, B., Wang, Q. and Zhang, J.A. "A long-term, high-quality, high-vertical-resolution GPS dropsonde dataset for hurricane and other studies", Bulletin of the American Meteorological Society, 96(6), pp. 961-973 (2015).

147. Ruf, C., Unwin, M., Dickinson, J., Rose, R., Rose, D., Vincent, M. and Lyons, A. "CYGNSS: enabling the future of hurricane prediction [remote sensing satellites]", IEEE Geoscience and Remote Sensing Magazine, 1(2), pp. 52-67 (2013).

148. Chen, S.S. and Curcic, M. "Ocean surface waves in Hurricane Ike (2008) and Superstorm Sandy (2012): Coupled model predictions and observations", Ocean Modelling, 103, pp. 161-176 (2016).

149. Subramanian, D., Salazar, J., Duenas-Osorio, L. and Stein, R. "Constructing and validating geographically refined HAZUS-MH4 hurricane wind risk models: a machine learning approach", ATC \& SEI Conference on Advances in Hurricane, pp. 1056-1066 (2013).

150. Pinelli, J.P., Simiu, E., Gurley, K., Subramanian, C., Zhang, L., Cope, A., Filliben, J.J. and Hamid, S. "Hurricane damage prediction model for residential structures", Journal of Structural Engineering, 130(11), pp. 1685-1691 (2004).

151. Li, Y. and Ellingwood, B.R. "Hurricane damage to residential construction in the US: Importance of uncertainty modeling in risk assessment", Engineering Structures, 28(7), pp. 1009-1018 (2006).
152. Chung, Y.S., Lin, N. and Vanmarcke, E. "Hurricane damage and loss estimation using an integrated vulnerability model", Natural Hazards Review, 12(4), pp. 184-189 (2010).

153. Subramanian, D., Salazar, J., Duenas-Osorio, L. and Stein, R. "Building and validating geographically refined hurricane wind risk models for residential structures", Natural Hazards Review, 15(3), 04014002 (10 pages) (2013).

154. Grayson, J.M., Pang, W. and Schiff, S. "Building envelope failure assessment framework for residential communities subjected to hurricanes", Engineering Structures, 51, pp. 245-258 (2013).

155. Taskin, S. and Lodree Jr, E.J. "A Bayesian decision model with hurricane forecast updates for emergency supplies inventory management", Journal of the Operational Research Society, 62(6), pp. 10981108 (2011).

156. Guikema, S.D., Nateghi, R., Quiring, S.M., Staid, A., Reilly, A.C. and Gao, M. "Predicting hurricane power outages to support storm response planning", IEEE Access, 2, pp. 1364-1373 (2014).

157. Sippel, J.A. and Zhang, F. "Factors affecting the predictability of Hurricane Humberto (2007)", Journal of the Atmospheric Sciences, 67(6), pp. 1759-1778 (2010).

158. Davies-Jones, R., Trapp, R.J. and Bluestein, H.B. "Tornadoes and tornadic storms", In Severe Convective storms American Meteorological Society: Boston, MA, pp. 167-221 (2001).

159. Church, C., Burgess, D., Doswell, C. and DaviesJones, R. "The tornado: its structure, dynamics, prediction, and hazards", Washington DC American Geophysical Union Geophysical Monograph Series, 79 (1993).

160. Golden, J.H. and Adams, C.R. "The tornado problem: Forecast, warning, and response", Natural Hazards Review, 1(2), pp. 107-118 (2000).

161. Edwards, R. "Tropical cyclone tornadoes: A review of knowledge in research and prediction", Electronic Journal of Severe Storms Meteorology, 7(6), pp. 1-61 (2012).

162. Edwards, R., LaDue, J.G., Ferree, J.T., Scharfenberg, K., Maier, C. and Coulbourne, W.L. "Tornado intensity estimation: Past, present, and future", Bulletin of the American Meteorological Society, 94(5), pp. 641-653 (2013).

163. Brotzge, J. and Donner, W. "The tornado warning process: A review of current research, challenges, and opportunities", Bulletin of the American Meteorological Society, 94(11), pp. 1715-1733 (2013).

164. Desrochers, P.R. and Donaldson Jr, R.J. "Automatic tornado prediction with an improved mesocyclonedetection algorithm", Weather and Forecasting, $7(2)$, pp. 373-388 (1992). 
165. Marzban, C. and Stumpf, G.J. "A neural network for tornado prediction based on Doppler radar-derived attributes", Journal of Applied Meteorology, 35(5), pp. 617-626 (1996).

166. Marzban, C., Mitchell, E.D.W. and Stumpf, G.J. "The notion of "best predictors": an application to tornado prediction", Weather and Forecasting, 14(6), pp. 1007-1016 (1999).

167. Marzban, C. "A neural network for tornado diagnosis: Managing local minima", Neural Computing \& Applications, 9(2), pp. 133-141 (2000).

168. Trafalis, T., Ince, H. and Richman, M. "Tornado detection with support vector machines", In Proceedings of the International Conference on Computational Science, Springer, Berlin, Heidelberg, pp. 289-298 (2003).

169. Trafalis, T., Santosa, B. and Richman, M. "Rulebased support vector machine classifiers applied to tornado prediction", Computational Science, 2004, pp. 678-684 (2004).

170. Son, H.J. and Trafalis, T. "Detection of tornados using an incremental revised support vector machine with filters", Computational Science, 2006, pp. 506513 (2006).

171. Trafalis, T.B., Adrianto, I., Richman, M.B. and Lakshmivarahan, S. "Machine-learning classifiers for imbalanced tornado data", Computational Management Science, 11(4), pp. 403-418 (2014).

172. Lakshmanan, V., Adrianto, I., Smith, T. and Stumpf, G. "A spatiotemporal approach to tornado prediction", In Proceedings on IEEE International Joint Conference in Neural Networks, Montreal, Quebec, Canada, pp. 1642-1647 (2005).

173. Ponz-Tienda, J.L., Pellicer, E., Benlloch-Marco, J. and Andrés-Romano, C. "Fuzzy project scheduling problem with minimal generalized relations", Computer-Aided Civil and Infrastructure Engineering, 30(11), pp. 872-891 (2015).

174. Liu, S., Xue, M. and Xu, Q. "Using wavelet analysis to detect tornadoes from Doppler radar radialvelocity observations", Journal of Atmospheric and Oceanic Technology, 24(3), pp. 344-359 (2007).

175. Wang, Y., Yu, T.Y., Yeary, M., Shapiro, A., Nemati, S., Foster, M., Andra Jr., D.L. and Jain, M. "Tornado detection using a neuro-fuzzy system to integrate shear and spectral signatures", Journal of Atmospheric and Oceanic Technology, 25(7), pp. 1136-1148 (2008).

176. Potvin, C.K., Shapiro, A., Yu, T.Y., Gao, J. and Xue, M. "Using a low-order model to detect and characterize tornadoes in multiple-Doppler radar data", Monthly Weather Review, 137(4), pp. 1230-1249 (2009).

177. Yu, K., Wang, D., Ding, W., Pei, J., Small, D.L., Islam, S. and $\mathrm{Wu}, \mathrm{X}$. "Tornado forecasting with multiple Markov boundaries", In Proceedings of the 21st ACM SIGKDD International Conference on Knowledge Discovery and Data Mining, Sydney, NSW, Australia, pp. 2237-2246 (2015).

178. Elsner, J.B. and Widen, H.M. "Predicting spring tornado activity in the central Great Plains by 1 March", Monthly Weather Review, 142(1), pp. 259267 (2014).

179. Brooks, H.E. "On the relationship of tornado path length and width to intensity", Weather and Forecasting, 19(2), pp. 310-319 (2004).

180. Eppelbaum, L.V. "Non-stochastic long-term prediction model for US tornado level", Natural Hazards, 69(3), pp. 2269-2278 (2013).

181. Xue, M., Hu, M. and Schenkman, A.D. "Numerical prediction of the 8 May 2003 Oklahoma City tornadic supercell and embedded tornado using ARPS with the assimilation of WSR-88D data", Weather and Forecasting, 29(1), pp. 39-62 (2014).

182. Cheng, V.Y., Arhonditsis, G.B., Sills, D.M., Gough, W.A. and Auld, H. "Predicting the climatology of tornado occurrences in North America with a Bayesian hierarchical modeling framework", Journal of Climate, 29(5), pp. 1899-1917 (2016).

183. Simmons, K.M. and Sutter, D. "Tornado warnings, lead times, and tornado casualties: An empirical investigation", Weather and Forecasting, 23(2), pp. 246-258 (2008).

184. Simmons, K.M. and Sutter, D. "False alarms, tornado warnings, and tornado casualties", Weather, Climate, and Society, 1(1), pp. 38-53 (2009).

185. Simmons, K.M. and Sutter, D. "Fatality prediction for the 2011 tornado season based on historical extreme weather data", Natural Hazards Review, 15(3), 04014005 (2014).

186. Durage, S.W., Wirasinghe, S.C. and Ruwanpura, J. "Comparison of the Canadian and US tornado detection and warning systems", Natural Hazards, 66(1), pp. 117-137 (2013).

187. Mathews, A.J., Haffner, M. and Ellis, E.A. "GISbased modeling of tornado siren sound propagation: refining spatial extent and coverage estimations", International Journal of Disaster Risk Reduction, 23, pp. 36-44 (2017).

188. Wu, C.H., Huang, G.R. and Yu, H.J. "Prediction of extreme floods based on CMIP5 climate models: a case study in the Beijiang River basin, South Chin", Hydrology and Earth System Sciences, 19(3), pp. 1385-1399 (2015).

189. Waylen, P. and Woo, M.K. "Prediction of annual floods generated by mixed processes", Water Resources Research, 18(4), pp. 1283-1286 (1982).

190. Woo, M.K. and Waylen, P.R. "Areal prediction of annual floods generated by two distinct processes", $H y$ drological Sciences Journal, 29(1), pp. 75-88 (1984).

191. Schumann, A.H. "Flood risk assessment and management: How to specify hydrological loads, their consequences and uncertainties", Springer Science 
\& Business Media: Medford, MA, New York, USA (2011).

192. Ferraris, L., Rudari, R. and Siccardi, F. "The uncertainty in the prediction of flash floods in the northern Mediterranean environment", Journal of Hydrometeorology, 3(6), pp. 714-727 (2002).

193. Takeuchi, K. "Increasing vulnerability to extreme floods and societal needs of hydrological forecasting", Hydrological Sciences Journal, 46(6), pp. 869-881 (2001).

194. Jeyaseelan, A.T. "Droughts \& floods assessment and monitoring using remote sensing and GIS", In Satellite Remote Sensing and GIS Applications in Agricultural Meteorology, Dehra Dun, India, pp. 291313 (2003).

195. Cloke, H.L. and Pappenberger, F. "Ensemble flood forecasting: a review", Journal of Hydrology, 375(3), pp. 613-626 (2009).

196. Taylor, J., Man Lai, K., Davies, M., Clifton, D., Ridley, I. and Biddulph, P. "Flood management: prediction of microbial contamination in large-scale floods in urban environments", Environment International, 37(5), pp. 1019-1029 (2011).

197. Hossain, F., Maswood, M., Siddique-E-Akbor, A.H., Yigzaw, W., Mazumdar, L.C., Ahmed, T., Hossain, M., Shah-Newaz, S.M., Limaye, A., Lee, H., Pradhan, S., Shrestha, B., Bajracahrya, B., Biancamaria, S., Shum, C.K. and Turk, F.J. "A promising radar altimetry satellite system for operational flood forecasting in flood-prone Bangladesh", IEEE Geoscience and Remote Sensing Magazine, 2(3), pp. 27-36 (2014).

198. Hossain, F. "Towards formulation of a space-borne system for early warning of floods: Can costeffectiveness outweigh prediction uncertainty?", Natural Hazards, 37(3), pp. 263-276 (2006).

199. Al Nachar, R., Inaty, E., Bonnin, P.J. and Alayli, Y. "Towards an automatic image registration technique using edge dominant corners primitives", Integrated Computer-Aided Engineering, 22(1), pp. 1-19 (2015).

200. Hsu, W.Y. "A novel image registration algorithm for indoor and built environment applications", Computer-Aided Civil and Infrastructure Engineering, 30(10), pp. 802-814 (2015).

201. Baumgartner, J., Flesia, A.G., Gimenez, J. and Pucheta, J. "A new image segmentation framework based on two-dimensional hidden Markov models", Integrated Computer-Aided Engineering, 23(1), pp. 113 (2016).

202. Almeida, G., Biscaia, H., Melicio, F., Chastre, C. and Fonseca, J.M. "In-plane displacement and strain image analysis", Computer-Aided Civil and Infrastructure Engineering, 31(4), pp. 292-304 (2016).

203. Zhu, Z.H., Fu, J.Y., Yang, J.S. and Zhang, X.M. "Panoramic image stitching for arbitrary shaped tunnel lining inspection", Computer-Aided Civil and Infrastructure Engineering, 31(12), pp. 936-953 (2016).
204. Paris, P.C.D., Pedrino, E.C. and Nicoletti, M.C. "Automatic learning of image filters using Cartesian genetic programming", Integrated Computer-Aided Engineering, 22(2), pp. 135-151 (2015).

205. Kim, D., Rho, S. and Hwang, E. "Classification and indexing scheme of large-scale image repository for spatio-temporal landmark recognition", Integrated Computer-Aided Engineering, 22(2), pp. 201-213 (2015).

206. Sanchez, A., Moreno, A.B., Vélez, D. and Vélez, J.F. "Analyzing the influence of contrast in large-scale recognition of natural images", Integrated ComputerAided Engineering, 23(3), pp. 221-235 (2016).

207. Koziarski, M. and Cyganek, B. "Image recognition with deep neural networks in presence of noisedealing with and taking advantage of distortions", Integrated Computer-Aided Engineering, 24(4), pp. 337-350 (2017).

208. Kussul, N., Shelestov, A., Skakun, S. and Kravchenko, O. "Data assimilation technique for flood monitoring and prediction", International Journal Information Theories \& Applications, 15(1), pp. 76-83 (2008).

209. Campolo, M., Soldati, A. and Andreussi, P. "Artificial neural network approach to flood forecasting in the River Arno", Hydrological Sciences Journal, 48(3), pp. 381-398 (2003).

210. Villanueva, I. and Wright, N.G. "Linking Riemann and storage cell models for flood prediction", Institution of Civil Engineers-Water Management, 159(1), pp. 27-33 (2006).

211. Damle, C. and Yalcin, A. "Flood prediction using time series data mining", Journal of Hydrology, 333(2), pp. 305-316 (2007).

212. Jin, J.L., Cheng, J. and Wei, Y.M. "Forecasting flood disasters using an accelerated genetic algorithm: Examples of two case studies for China", Natural Hazards, 44(1), pp. 85-92 (2008).

213. Smith, P.J., Panziera, L. and Beven, K.J. "Forecasting flash floods using data-based mechanistic models and NORA radar rainfall forecasts", Hydrological Sciences Journal, 59(7), pp. 1403-1417 (2014).

214. Azami, N.I.A., Yusoff, N. and Ku-Mahamud, K.R. "Data acquisition and discretization for flood correlation model", Journal of Theoretical and Applied Information Technology, 95(4), pp. 879-889 (2017).

215. Javadnejad, F., Waldron, B. and Hill, A. "LITE Flood: simple GIS-based mapping approach for realtime redelineation of multifrequency floods", Natural Hazards Review, 18(3), 04017004 (13 pages) (2017).

216. Porporato, A. and Ridolfi, L. "Multivariate nonlinear prediction of river flows", Journal of Hydrology, 248(1), pp. 109-122 (2001).

217. Montaldo, N., Ravazzani, G. and Mancini, M. "On the prediction of the Toce alpine basin floods with distributed hydrologic models", Hydrological Processes, 21(5), pp. 608-621 (2007). 
218. Komma, J., Reszler, C., Blöschl, G. and Haiden, T. "Ensemble prediction of floods? Catchment nonlinearity and forecast probabilities", Natural Hazards and Earth System Science, 7(4), pp. 431-444 (2007).

219. Zeinivand, H. and De Smedt, F. "Prediction of snowmelt floods with a distributed hydrological model using a physical snow mass and energy balance approach", Natural Hazards, 54(2), pp. 451-468 (2010).

220. Ma, H. and Fu, X. "Real time prediction approach for floods caused by failure of natural dams due to overtopping", Advances in Water Resources, 35, pp. 10-19 (2012).

221. Webster, P.J., Toma, V.E. and Kim, H.M. "Were the 2010 Pakistan floods predictable?", Geophysical Research Letters, 38(4), pp. 1-5 (2011).

222. Nester, T., Komma, J., Viglione, A. and Blöschl, G. "Flood forecast errors and ensemble spread-A case study", Water Resources Research, 48(10), pp. 1-19 (2012).

223. Chen, M., Mao, S. and Liu, Y. "Big data: A survey", Mobile Networks and Applications, 19(2), pp. 171-209 (2014).

224. Kim, G.H., Trimi, S. and Chung, J.H. "Big-data applications in the government sector", Communications of the ACM, 57(3), pp. 78-85 (2014).

225. Lee, J.G. and Kang, M. "Geospatial big data: challenges and opportunities", Big Data Research, 2(2), pp. 74-81 (2015).

226. Li, S., Dragicevic, S., Castro, F.A., Sester, M., Winter, S., Coltekin, A., Pettit, C., Jiang, B., Haworth, J., Stein, A. and Cheng, T. "Geospatial big data handling theory and methods: A review and research challenges", ISPRS Journal of Photogrammetry and Remote Sensing, 115, pp. 119-133 (2016).

227. Yang, C., Yu, M., Hu, F., Jiang, Y. and Li, Y. "Utilizing cloud computing to address big geospatial data challenges", Computers, Environment and Urban Systems, 61, pp. 120-128 (2017).

228. Laney, D. "3-D data management: controlling data volume, velocity and variety", META Group Research Note, 949, pp. 1-4 (2001).

229. Gantz, J. and Reinsel, D. "Extracting value from chaos", IDCiView, 2011, pp. 1-12 (2011).

230. Dhamodaran, S., Sachin, K.R. and Kumar, R. "Big data implementation of natural disaster monitoring and alerting system in real time social network using Hadoop technology", Indian Journal of Science and Technology, 8(22), pp. 1-4 (2015).

231. Adeli, H. and Kumar, S., Distributed Computer-aided Engineering for Analysis, Design, and Visualization, CRC Press, Boca Raton, Florida (1999).
232. Song, X., Zhang, Q., Sekimoto, Y., Shibasaki, R., Yuan, N.J. and Xie, X. "Prediction and simulation of human mobility following natural disasters", $A C M$ Transactions on Intelligent Systems and Technology, 8(2), pp. 1-23 (2016).

233. Terra Seismic, http://www.terraseismic.com/, accessed September 1 (2017).

234. Preis, T., Moat, H.S., Bishop, S., Treleaven, P. and Stanley, H.E. "Quantifying the digital traces of Hurricane Sandy on Flickr", Scientific Reports, 3, pp. 1-3 (2013).

235. Shelton, T., Poorthuis, A., Graham, M. and Zook, M. "Mapping the data shadows of Hurricane Sandy: Uncovering the sociospatial dimensions of "big data", Geoforum, 52, pp. 167-179 (2014).

236. Chatfield, A.T. and Reddick, C.G. "Understanding risk communication gaps through e-government website and twitter hashtag content analyses: the case of Indonesia's Mt. Sinabung eruption", Journal of Homeland Security and Emergency Management, 12(2), pp. 351-385 (2015).

237. Miyoshi, T., Lien, G.Y., Satoh, S., Ushio, T., Bessho, K., Tomita, H., Nishizawa, S., Yoshida, R., Adachi, S., Liao, J., Gerofi, B., Ishikawa, Y., Kunii, M., Ruiz, J., Maejima, Y., Otsuka, S., Otsuka, M., Okamoto, K. and Seko, H. "Big data assimilation, toward postpetascale severe weather prediction: an overview and progress", Proceedings of the IEEE, 104(11), pp. 2155-2179 (2016).

238. Yusoff, A., Din, N.M., Yussof, S. and Khan, S.U. "Big data analytics for flood information management in Kelantan, Malaysia", IEEE Student Conference on Research and Development (SCOReD), Malaysia, Kuala Lumpur, pp. 311-316 (2015).

239. Zhuang, Y., Yu, K., Wang, D. and Ding, W. "An evaluation of big data analytics in feature selection for long-lead extreme floods forecasting", 13th International IEEE Conference on Networking, Sensing, and Control (ICNSC), Distrito Federal, Mexico, pp. 1-6 (2016).

240. Rathore, M.M., Ahmad, A., Paul, A. and Rho, S. "Urban planning and building smart cities based on the internet of things using big data analytics", Computer Networks, 101, pp. 63-80 (2016).

241. Chai, C. and Wong, Y.D. "Fuzzy cellular automata models for signalized intersections", Computer-Aided Civil and Infrastructure Engineering, 30(12), pp. 951964 (2015).

242. Hsu, W.Y. "Assembling a multi-feature EEG classifier for left-right motor data using wavelet-based fuzzy approximate entropy for improved accuracy", International Journal of Neural Systems, 25(8), 1550037 (13 pages) (2015). 
243. Peng, H., Wang, J., Shi, P., Perez-Jimenez, M.J. and Riscos-Nunez, A. "An extended membrane system with active membranes to solve automatic fuzzy clustering problems", International Journal of Neural Systems, 26(3), 1650004 (17 pages) (2016).

244. Borrmann, A., Kolbe, T.H., Donaubauer, A., Steuer, H., Jubierre, J.R. and Flurl, M. "Multi-scale geometric-semantic modeling of shield tunnels for GIS and BIM applications", Computer-Aided Civil and Infrastructure Engineering, 30(4), pp. 263-281 (2015).

\section{Biographies}

Juan Pablo Amezquita-Sanchez graduated from University of Guanajuato in 2007 with a BSc Degree in Electronic Engineering. He received his MSc degree in Electrical Engineering from University of Guanajuato and the $\mathrm{PhD}$ degree in Mechatronics from the Autonomous University of Queretaro, Queretaro, Mexico in 2009 and 2012, respectively. He was a Postdoctoral Visiting Scholar in The Ohio State University during 2013-2014. He is currently a full time Professor at the Faculty of Engineering, Autonomous University of Queretaro, Campus San Juan del Rio, Queretaro, Mexico. He is a member of the Mexican National Research System (SNI), level 1. He has published in the areas of structural health monitoring, signal processing, and mechatronics.

Martin Valtierra-Rodriguez received the BE degree in Mechatronics Engineering and the ME degree in Electrical Engineering from the University of Guanajuato, Guanajuato, Mexico in 2008 and 2010, respectively, and the $\mathrm{PhD}$ degree in Mechatronics from the Autonomous University of Queretaro, San Juan del Río. Mexico, in 2013. He is currently a Professor with the Faculty of Engineering, Autonomous University of Queretaro and a member of the Mexican National Research System (level 1). His current research interests include signal processing, expert systems, and applications of mechatronics.

Hojjat Adeli is a Professor of Civil, Environmental, and Geodetic Engineering at The Ohio State University. He has authored over 540 research publications including 15 pioneering computational books, since he received his $\mathrm{PhD}$ from Stanford University in 1976 at the age of 26 . In 1998, he received the University Distinguished Scholar Award from The Ohio State University "in recognition of extraordinary accomplishment in research and scholarship". Among his numerous other awards and honors are the Lumley Research Award in Recognition of Outstanding Research Accomplishments (quadruple winner), Peter L. and Clara M. Scott Award for Excellence in Engineering Education, Charles E. MacQuigg Outstanding Teaching Award from OSU, a Special Medal in Recognition of Outstanding Contribution to the Development of Computational Intelligence from the Polish Neural Network Society, the Eduardo Renato Caianiello Award "for Having Realized the Model of Interdisciplinary Scientist in the Pursuit of E.R. Caianiello Project and for the Excellent Results in Engineering and Neuroscience", from the Italian Society of Neural Networks, an Honorary Doctorate from Vilnius Gediminas Technical University, Lithuania, and membership in the Spanish Royal Engineering Society. He received the ASCE Construction Management Award in 2006. In 1998, he was awarded a United States patent for his neural dynamics model for design automation and optimization (jointly with a former $\mathrm{PhD}$ student). He is a Distinguished Member of ASCE and a Fellow of AAAS, IEEE, AIMBE, and the American Neurological Association. 